\title{
Volvulus of Colon Sigmoide in the General Surgery Department of Chu Gabriel Toure
}

\author{
Maïga Amadou1 ${ }^{*}$, Diakité Ibrahima², Bah Amadou², Diallo Aly Boubacar1, Traoré Bathio1, \\ Moussa Diassana1, Sidibé Boubacar Yoro², Koné Tani², Doumbia Arouna Adama², \\ Traoré Amadou'2, Saye Zakari², Diallo Mamadou ${ }^{3}$, Konaté Moussa ${ }^{3}$, Saadé Oumou Hélène², \\ Kanté Lassana², Konaté Madiassa², Dembélé Souleymane², Samaké Moussa², \\ Dembélé Bakary Tientigui ${ }^{2}$, Traoré Alhassane ${ }^{2}$, Togo Adégné ${ }^{2}$
}

${ }^{1}$ General Surgery Department, University Hospital, Bamako, Mali

${ }^{2}$ General Surgery Department, Sikasso Hospital, Sikasso, Mali

${ }^{3}$ Reference Center of Commune VI, Bamako, Mali

Email: *amadoumaiga3@gmail.com

How to cite this paper: Amadou, M., Ibrahima, D., Amadou, B., Boubacar, D.A., Bathio, T., Diassana, M., Yoro, S.B., Tani, K. Adama, D.A., Amadou, T., Zakari, S., Mamadou, D., Moussa, K., Hélène, S.O., Lassana, K., Madiassa, K., Souleymane, D., Moussa, S., Tientigui, D.B., Alhassane, T. and Adégné, T. (2022) Volvulus of Colon Sigmoide in the General Surgery Department of Chu Gabriel Toure. Surgical Science, 13, 46-52.

https://doi.org/10.4236/ss.2022.131008

Received: November 9, 2021

Accepted: January 25, 2022

Published: January 28, 2022

Copyright $\odot 2022$ by author(s) and Scientific Research Publishing Inc. This work is licensed under the Creative Commons Attribution International License (CC BY 4.0).

http://creativecommons.org/licenses/by/4.0/

(c) (i) Open Access

\begin{abstract}
Introduction: Sigmoid colon volvulus is a medico-surgical emergency which represents a common cause of colonic occlusion, it is characterized by strangulation of the sigmoid loop around its meso colic axis producing low mechanical occlusion [1]. Apart from this form conventionally described, the volvulus of the sigmoid colon can occur along an organoaxial axis. This form has been highlighted in the literature thanks to the diagnostic contribution of multi-detector scanners [2]. Objective: To determine the hospital frequency of sigmoid colon volvulus; to write the clinical and para-clinical aspects of sigmoid colon volvulus; write down the different treatments used for the management of sigmoid colon volvulus. Material and methods: This was a retrospective and prospective study that took place from January 2008 to December 2020 in the General Surgery Department of Gabriel Touré. The retrospective phase ran from January 2008 to December 2019 and the prospective phase from January 2020 to December 2020. Results: From January 2008 to December 2020, we collected 320 cases of patients operated on for sigmoid colon volvulus out of 7989 surgical emergencies over a 12-year period, or $3.64 \%$. In our study, the most represented age group was between 16 and 60 years old, i.e. $81.88 \%$. The mean age was $42.6 \pm 17.4$ years with extremities of 16 and 90 years. The male sex was the most represented, $89 \%$ with a sex ratio of 8.41 . The surgical history was found in $13.75 \%$ of our patients. The clinic was dominated by abdominal pain (100\%), meteorism (100\%), and gas and matter arrest (91.3\%). The most common radiological image found in the ASP was the double jamb, i.e. $74.69 \%$ of cases. We found sigmoid necrosis in $18.13 \%$ of cases. We found an absence of necrosis in the majority of cases, i.e.
\end{abstract}


91.56\%. The most performed operative procedure in our patients was the RACR, i.e. $75.63 \%$ of cases. The reoperation was performed in only $5.94 \%$ of our patients. Complications were grade V in $42.55 \%$ according to the Clavin

Dindo classification.

\section{Keywords}

Sigmoid Volvulus, General Surgery Department

\section{Introduction}

Sigmoid colon volvulus is a medico-surgical emergency that represents a common cause of colonic occlusion, it is characterized by strangulation of the sigmoid loop around its meso colic axis producing low mechanical occlusion [1]. Apart from this form conventionally described, the volvulus of the sigmoid colon can occur along an organoaxial axis. This form has been highlighted in the literature thanks to the diagnostic contribution of multi-detector scanners [2].

It represents $50 \%$ of intestinal obstructions in developing countries against only $5 \%$ in the West [3]. In the United States of America, it is the third leading cause of colon obstruction after cancer and diverticulosis [4]. In western countries, sigmoid colon volvulus is common in elderly subjects (after 70 years) while it is the prerogative of young adults in African countries [5] [6]. The etiology remains unknown, however, there are factors that are implicated in the occurrence of this pathology.

In Europe, pregnancy, pelvic tumor, surgery in the small pelvis associated with constipation and/or dolichocolon favor the development of the pathology [7], some psychiatric conditions (schizophrenia, senile dementia), Chagas disease for a quarter of patients in Brazil, the vegetarian diet (because of the presence in significant quantities of cellulose residues inside the intestine) [8]. In Africa, dolichocolon, food rich in non-absorbable fiber and tendency to constipation have been implicated in the occurrence of sigmoid volvulus [9]. The clinical examination, by the presence of the sign of VON WAHL: meteorism (tympanic, asymmetric, renitent) and the x-ray of the abdomen without preparation (ASP) are usually sufficient for the diagnosis.

The therapeutic attitude in emergency is controversial and calls for a variety of techniques. Emergency endoscopy, if it is available, is becoming increasingly important in Western and Maghrebian countries. Surgery remains necessary either urgently in case of failure of non-operative treatments or necrosis, or postponed due to the high rate of recurrence. In the absence of treatment, spontaneous progression, regardless of the mechanism, is towards ischemia and then necrosis of the volvulated digestive segment.

\section{Objectives}

To determine the hospital frequency of sigmoid colon volvulus; to write the 
clinical and para-clinical aspects of sigmoid colon volvulus; write down the different treatments used for the management of sigmoid colon volvulus.

\section{Methodology}

This was a retrospective and prospective study that took place from January 2008 to December 2020 in the General Surgery department of Gabriel Touré. The retrospective phase ran from January 2008 to December 2019 and the prospective phase from January 2020 to December 2020.

\section{Results}

During our study period, we collected 320 cases of patients operated on for sigmoid colon volvulus out of 7989 surgical emergencies, i.e. $3.64 \%$; $76.92 \%$ of digestive tracts (416); 29.44\% of acute intestinal obstruction (1087). In our study, the most represented age group was between 16 and 60 years old, i.e. $81.88 \%$. The mean age was $42.6 \pm 17.4$ years with extremities of 16 and 90 years (Table 1). The male sex was the most represented, $89 \%$ with a sex ratio of 8.41 (Figure 1). The surgical history was found in $13.75 \%$ of our patients (Table 2 ). The clinic was dominated by abdominal pain (100\%), meteorism (100\%), and gas and matter arrest (91.3\%) (Table 3). The most common radiological image found in ASP was the double leg, i.e. $74.69 \%$ of cases (Table 4). We found sigmoid necrosis in $18.13 \%$ of cases. We found an absence of necrosis in the majority of cases, i.e. $91.56 \%$ (Table 5). The operative procedure the most performed in our patients was the RACR, i.e. $75.63 \%$ of cases (Table 6). The reoperation was performed in

Table 1. Age of patients.

\begin{tabular}{ccc}
\hline Age of patients & Effective & Percentage (\%) \\
\hline$[16-60]$ & 262 & $\mathbf{8 1 . 8 8}$ \\
61 and more & 58 & 18.13 \\
Total & 320 & 100.00 \\
\hline
\end{tabular}

The most represented age group was between 16 and 60 years old, i.e. $81.88 \%$. The mean age was $42.6 \pm 17.4$ years with extremities of 16 and 90 years.

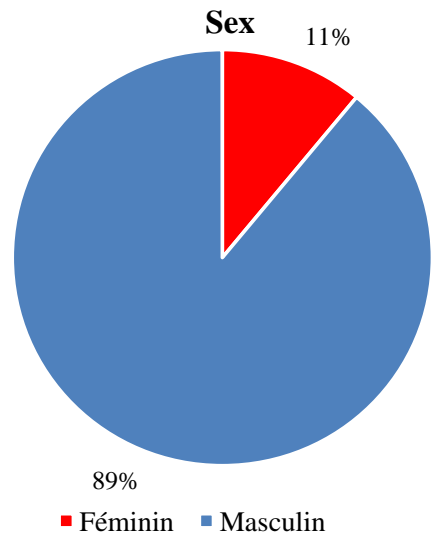

Figure 1. sex ratio. 
Table 2. Surgical history.

\begin{tabular}{ccc}
\hline Surgical history & Effective & Percentage (\%) \\
\hline Yes & 44 & 13.75 \\
No & 276 & 86.25 \\
Total & 320 & 100.00 \\
\hline
\end{tabular}

The surgical history was found in $13.75 \%$ of our patients.

Table 3. Interrogation signs.

\begin{tabular}{ccc}
\hline Signs during interrogation & Effective & Percentage (\%) \\
\hline Abdominal pain & 320 & 100 \\
Meteorism & 320 & 100 \\
Material and gas shutdown & 292 & 91.3 \\
Abdominal distension & 46 & 14.4 \\
Vomiting & 272 & 85.0 \\
\hline
\end{tabular}

The clinic was dominated by abdominal pain (100\%), meteorism (100\%), and gas and matter arrest $(91.3 \%)$.

Table 4. X-ray signs.

\begin{tabular}{ccc}
\hline Hydro-aeric level at the ASP & Effective & Percentage (\%) \\
\hline Double jamb & 239 & 74.69 \\
Taller than wide & 67 & 20.94 \\
Mixed & 8 & 2.50 \\
Central & 3 & 0.94 \\
Normal & 1 & 0.31 \\
Not done & 2 & 0.63 \\
Total & 320 & 100.00 \\
\hline
\end{tabular}

The most performed operative procedure in our patients was RACR, i.e. $75.63 \%$ of cases.

Table 5. Sigmoid state.

\begin{tabular}{ccc}
\hline Sigmoid state & Effective & Percentage (\%) \\
\hline With necrosis & 58 & 18.13 \\
Without necrosis & 262 & 81.87 \\
Total & 320 & 100.00 \\
\hline
\end{tabular}

We found sigmoid necrosis in $18.13 \%$ of cases.

Table 6. Intraoperativeprocedures.

\begin{tabular}{ccc}
\hline Intraoperative procedures & Effective & Percentage (\%) \\
\hline RACR & 249 & 77.82 \\
Sigmoidectomy + colostomy & 38 & 11.87 \\
\hline
\end{tabular}


Continued

$\begin{array}{ccc}\text { RAJJ + colostomy according to Hartmann } & 16 & 5.00 \\ \text { Devolvulation } & 10 & 3.12 \\ \text { RACR + Ileostomy } & 6 & 1.88 \\ \text { RACR + jejunostomy } & 1 & 0.31 \\ \text { Total } & 320 & 100.00\end{array}$

The most performed operative procedure in our patients was RACR, i.e. $75.63 \%$ of cases.

Table 7. Prevalence.

\begin{tabular}{ccc}
\hline Authors. & Effective/sampling time & Percentage/year \\
\hline Codina, Espagne, 2011 [2] & $54 / 12$ year & 4.5 case/year \\
Cirocchi, Italie, 2010 [3] & $23 / 12$ year & 1.9 case/year \\
Naseer, Pakistan, 2010 [4] & $30 / 2$ year & 15 case/year \\
Zhonghua, China 2011[5] & $52 / 8$ year & 6.5 case/year \\
Dembélé C, Mali 2014 [1] & $54 / 4$ year & 13.5 case/year \\
Notre étude, Mali, 2020 & $320 / 12$ year & 26.7 case/year. \\
\hline
\end{tabular}

We found sigmoid necrosis in $18.13 \%$ of cases.

only $5.94 \%$ of our patients. Complications were grade $\mathrm{V}$ in $42.55 \%$ according to the Clavin Dindo classification.

\section{Comments}

Our prevalence of sigmoid colon volvulus was 26.7 cases/year. This prevalence seems to be higher than those in the literature, varying from 1.9 to 15 cases/year [2] [3] [4] [5]. This geographic difference has been reported by several authors [6] [7] (Table 7).

The clinic was dominated by abdominal pain (100\%), meteorism (100\%), and gas and matter arrest (91.3\%). This result is comparable to those of Kalli M. in Chad in 2015 [10] who reported abdominal pain (91.2\%), abdominal distension (88.6\%), stopping of materials and gas (73.6\%) and vomiting. In our study, the radiological image most often found in the ASP was the double jamb in 239 cases, i.e. 74.69\% of cases. Cissé M. [11] in 2012 and Diarra A.G. [12] in 2009 found a double-leg image respectively 65\% (65 cas) and 68.8\% (138 cases) in Mali. Levsky J.M. in the US toruvated 76\% (21 cases) of double-jamb image in 2010 [13]. Atamanalp in Turkey found 76\% (453 cases) in 2011. [8]. In our study, the most performed operative procedure was Sigmoidectomy with colorectal anastomosis in $75.63 \%$ Complications were noted in 40 patients or $12.50 \%$. Among which the parietal suppuration the most represented with $32.50 \%$ followed by peritonitis by release in $10 \%$ of cases. This morbidity rate does not differ from those of the African and Asian series [11] [12] [14] [15] [16]. Mortality from sigmoid volvulus is relatively high. In our study, the mortality rate was $6.25 \%$ or 
20 patients. Cissé M. [11] in Mali and Atamanalp in Turkey in 2013 found a mortality rate of $14 \%$ (100 patients) and 10\% (40 patients), respectively.

\section{Conclusion}

Sigmoid volvulus is a serious surgical emergency requiring early management. Its therapeutic modalities are controversial. As endoscopic decompression is not yet feasible in our country, sigmoidectomy with one-step colorectal anastomosis represents an alternative in Mali.

\section{Conflicts of Interest}

The authors declare no conflicts of interest regarding the publication of this paper.

\section{References}

[1] Dembélé, C. (2014) Volvulus du sigmoïde dans le service de chirurgie générale de l'hôpital de Sikasso. Thèse de Médecine, FMOS (Framhaldsskólinn í Mosfellsbæ), $\mathrm{N}^{\circ} 61,99 \mathrm{p}$.

[2] Codina Cazador, A., Farres Coll, R., Olivet Pujol, F., et al. (2011) Colonic Volvulus and Recurrence of Volvulus: What Should We Do? Cirugía Española, 89, 237-242. https://doi.org/10.1016/S2173-5077(11)70031-X

[3] Cirocchi, R., Farinella, E., La Mura, F., Morelli, U., Trastulli, S., Milani, D., et al. (2010) The Sigmoid Volvulus: Surgical Timing and Mortality for Different Clinical Types. World Journal of Emergency Surgery, 5, Article No. 1. https://doi.org/10.1186/1749-7922-5-1

[4] Naseer, A., Ahmad, S. and Safirullah, N. (2010) One Stage Emergency Resection and Primary Anastomosis for Sigmoid Volvulus. Journal of College of Physicians and Surgeons Pakistan, 20, 307-309.

[5] Zhong, Y.S., Yao, L.Q., Xu, J.M., Zhou, P.H., Chen, W.-F. and Qin, X.-Y. (2011) Emergency Colonoscopy in the Diagnosis and Treatment of Acute Colorectal Obstruction. National Medical Journal of China, 91, 524-527.

[6] Agaoglu, N.M., Yücel, Y. and Türkytlmaz, S. (2005) Surgical Traitment of the Sigmoid Volvulus. Acta Chirurgica Belgica, 105, 365-368.

https://doi.org/10.1080/00015458.2005.11679737

[7] Doucouré, G. (1995) Traitement chirurgical du volvulus du côlon pelvien dans les services de chirurgie viscérale de l'hôpital national du Point G à propos de 56 cas. Thèse de Méd Bamako (Mali), 26.

[8] Atamanalp, S.S. and Ozturk, G. (2011) Sigmoid Volvulus in the Elderly: Outcomes of a 43-Year, 453 Patients Experience. Surgery Today, 41, 514-519. https://doi.org/10.2214/AJR.09.2580

[9] Traoré, H. (2012) Volvulus du colon sigmoïde dans le service de chirurgie « $A$ » au CHU du POINT G. Thèse de Méd Bamako (Mali), N61, 90 p.

[10] Kalli, M. (2015) Résultats du traitement du volvulus du sigmoïde à N'Djamena, Tchad. European Scientific Journal, 11, 245-253.

[11] Cissé, M. (2013) Volvulus du colon sigmoïde dans le service de chirurgie générale de l'hôpital Sominé DOLO de Mopti: 100 CAS. Thèse de Médecine, FMOS (Framhaldsskólinn í Mosfellsbæ), N51, 86 p. 
[12] Diarra, A.G. (2011) Volvulus du colon sigmoïde sans nécrose dans les services de chirurgie générale et pédiatrique du CHU Gabriel Touré: 138 cas. Thèse de médecine, Bamako, $\mathrm{N}^{\circ} 174$.

[13] Levsky, J.M., Den, E.I., DuBrow, R.A., Wolf, E.L. and Rozenblit, A.M. (2010) CT Findings of Sigmoid Volvulus. American Journal of Roentgenology, 194, 136-143. https://doi.org/10.2214/AJR.09.2580

[14] Atamanalp, S.S. (2013) Treatment of Sigmoid Volvulus: A Single-Center Experience of 952 Patients over 46.5 Years. Techniques in Coloproctology, 17 , 561-569. https://doi.org/10.1007/s10151-013-1019-6

[15] Mello, J.B. (1965) Volvulo sigmoid conduta. Arg Cir ClinExp, 28, 32-35.

[16] Ghariani, B., Houissa, H. and Sebai, F. (2010) Management of Sigmoid Volvulus. Tunisie Medicale, 88, 163-167. 